\title{
Synchronous Occurrence of a Hemorrhagic Hypothalamic Hamartoma and a Suprasellar Teratoma
}

\author{
Narayanam Anantha Sai Kiran ${ }^{\mathrm{a}}$ Nandita Ghosal ${ }^{\mathrm{b}}$ Sumit Thakar ${ }^{\mathrm{a}}$ \\ Alangar S. Hegde ${ }^{a}$ \\ Departments of a Neurosurgery and ${ }^{\mathrm{b}}$ Neuropathology, Sri Sathya Sai Institute of Higher Medical Sciences, \\ Bangalore, India
}

\section{Key Words}

Congenital lesion $\cdot$ Hamartoma $\cdot$ Hemorrhage $\cdot$ Pediatric

brain tumors $\cdot$ Suprasellar lesion $\cdot$ Synchronous $\cdot$ Teratoma

\begin{abstract}
Hypothalamic hamartomas have been reported to coexist with lesions like Rathke's cleft cyst and arachnoid cysts in the suprasellar or temporo-sylvian regions. This is the first report in indexed literature describing its association with a suprasellar teratoma. A 7-year-old girl presented with long-standing precocious puberty and generalized tonic-clonic seizures and recent-onset raised intracranial pressure. MRI done prior to the onset of symptomatic raised intracranial pressure revealed 2 distinct lesions in the suprasellar region. One was a midline, pedunculated lesion arising from the hypothalamus, with evidence of an old bleed within it. A separate lesion, with a wide base near the tuberculum sellae and a posteriorly directed conical tip, was noted in an adjacent sagittal cut. CT scan done at the time of admission demonstrated a re-bleed in the suprasellar region with blood in the lateral and third ventricles and gross hydrocephalus. The child was taken up for a ventriculoperitoneal shunt followed by complete excision of the lesions. Histopathologic exami-
\end{abstract}

nation confirmed the pedunculated lesion to be a hypothalamic hamartoma with evidence of hemorrhage, and the other to be a mature teratoma. Postoperative MRI confirmed complete excision of both the lesions. The child reported regression of precocious puberty and remained seizure-free until the last follow-up 6 months after surgery. A hypothesis based on a dysontogenetic mechanism is discussed to explain the unusual occurrence of the dual, seemingly unrelated pathologies. Hemorrhage into the hamartoma was an added oddity in this case.

Copyright $\odot 2012$ S. Karger AG, Basel

\section{Introduction}

A non-neoplastic, congenital lesion consisting of heterotopic neural tissue, the hypothalamic hamartoma $(\mathrm{HH})$, commonly presents with gelastic seizures and/or precocious puberty [1-3]. There have been anecdotal reports of its association with other congenital lesions like Rathke's cleft cyst [4] and arachnoid cysts in the suprasellar [5] and temporo-sylvian [6-8] regions. Our report discusses a hitherto undescribed synchronous association of this lesion with a teratoma, another congenital lesion

\section{KARGER}

Fax +41613061234 E-Mail karger@karger.ch www.karger.com
(C) 2012 S. Karger AG, Basel

$1016-2291 / 11 / 0476-0430 \$ 38.00 / 0$

Accessible online at:

www.karger.com/pne
Dr. Nandita Ghosal

Department of Neuropathology

Sri Sathya Sai Institute of Higher Medical Sciences

Whitefield, Bangalore 560066 (India)

Tel. +91 802841 1500, ext. 316, E-Mail nandita.ghosal@yahoo.in 

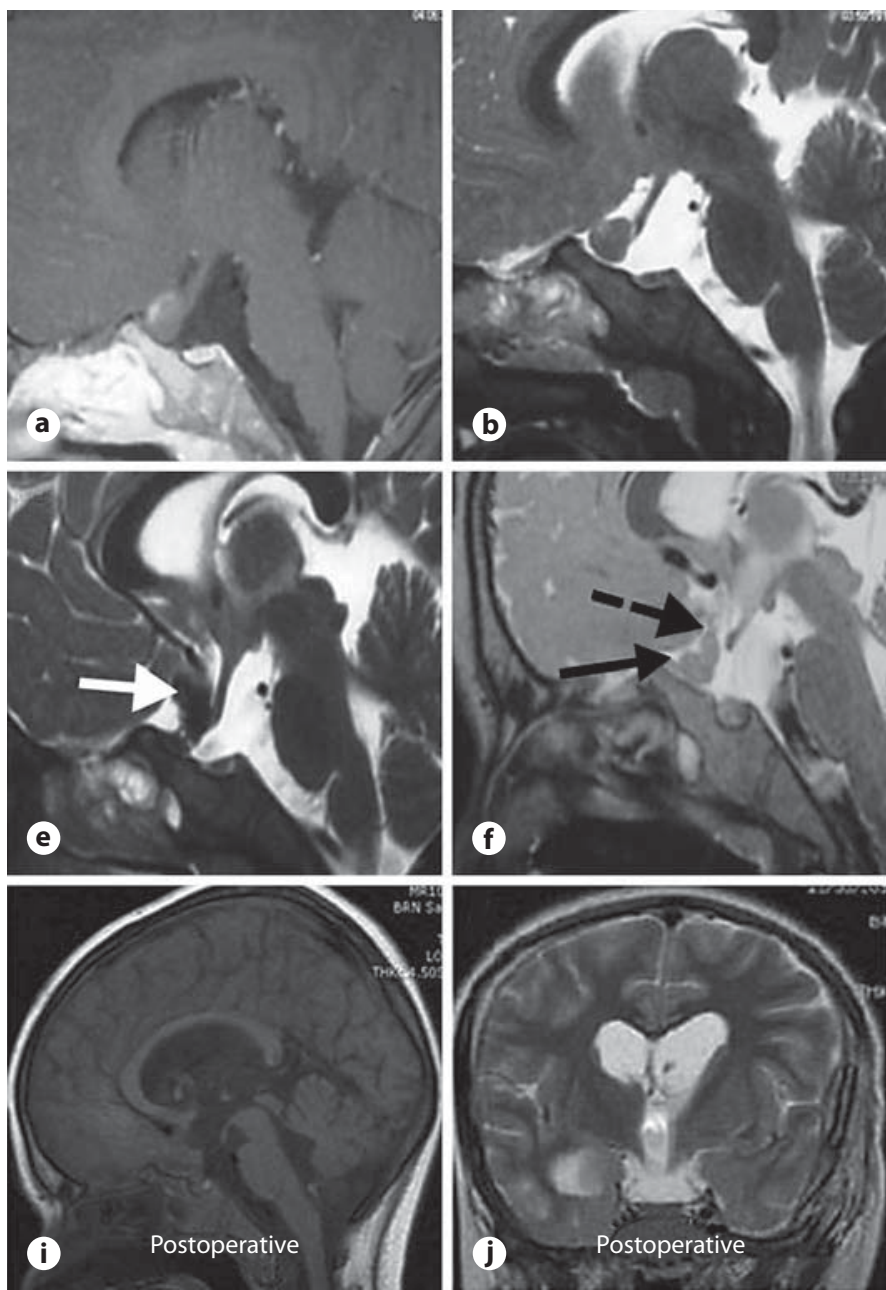

Fig. 1. Mid-sagittal a $\mathrm{T}_{1}$ contrast and $\mathbf{b} \mathrm{T}_{2}$-WI showing the isointense, pedunculated lesion arising from the region of the hypothalamus. c-e Axial $\mathrm{T}_{1}$ plain (c), coronal $\mathrm{T}_{2}(\mathbf{d})$, sagittal $\mathrm{T}_{2}$-WIs (e) showing a large circumscribed area of $\mathrm{T}_{1^{-}}$and $\mathrm{T}_{2}$-hypointensity (solid white arrows in c-e) in the hypothalamic lesion suggestive of an old bleed. $\mathbf{f}$ Sagittal $\mathrm{T}_{2}$-WI in a cut adjacent to that of the hypothalamic lesion, showing a separate, iso-intense lesion with a wide base (solid black arrow) in the region of the tuberculum
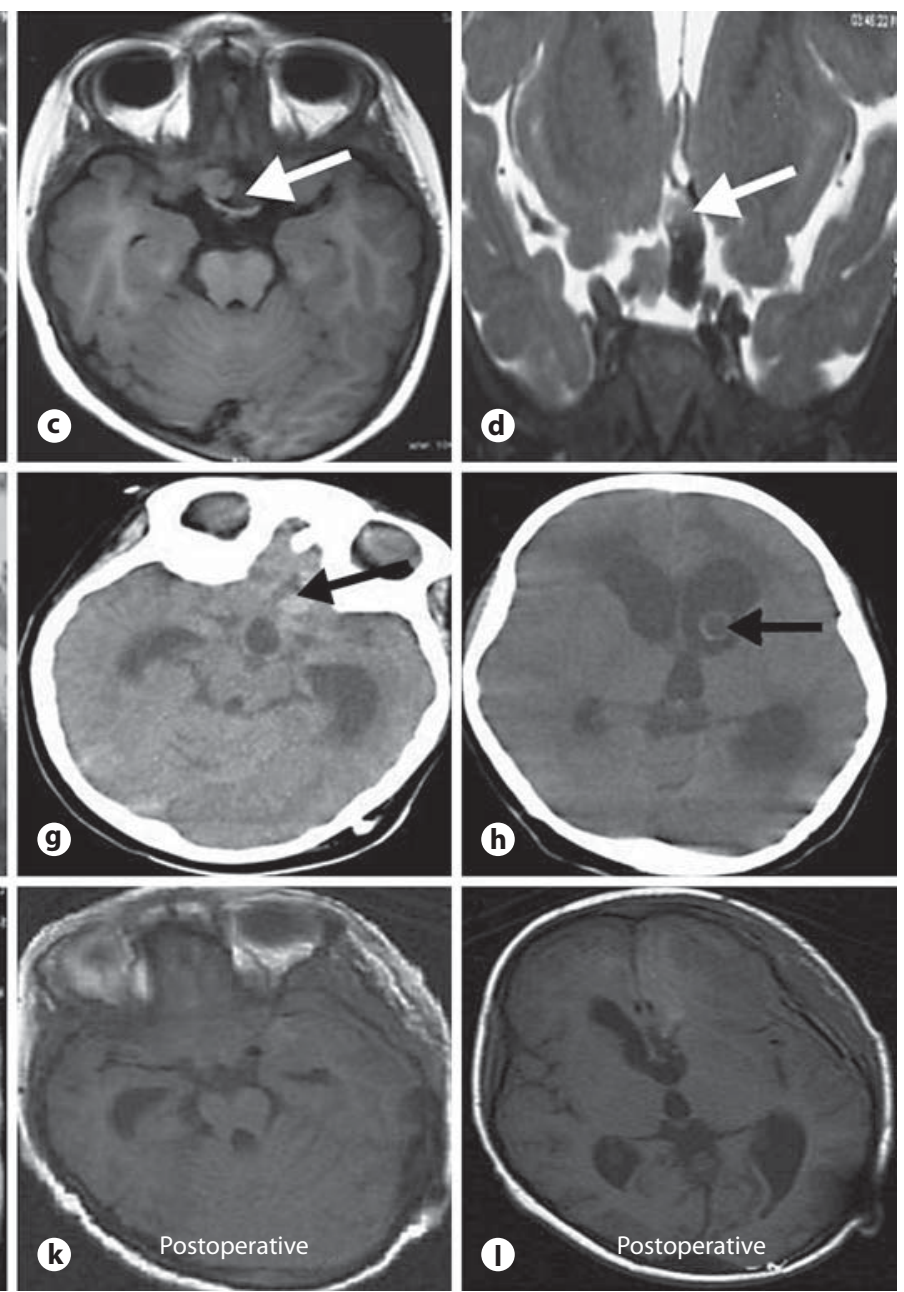

sellae, and the narrow tip (broken black arrow) directed posterosuperiorly. g, h Plain CT scan done at the time of admission showing re-bleed with blood in the suprasellar region (arrow in $\mathbf{g}$ )/left lateral ventricle (arrow in $\mathbf{h}$ ) and gross hydrocephalus with periventricular ooze. $\mathbf{i}-\mathbf{I}$ Postoperative $M R$ images, $\mathbf{i}$ sagittal $\mathrm{T}_{1}$, j coronal $\mathrm{T}_{2}$, and $\mathbf{k}$, I axial $\mathrm{T}_{1}$-WIs confirming total excision of the lesions and resolution of hydrocephalus.

very irritable. Other than papilledema on fundoscopy, her neurological examination was unremarkable. Systemic examination revealed the presence of secondary sexual characteristics. Her hormonal profile $\left(\mathrm{T}_{3}, \mathrm{~T}_{4}\right.$, TSH, cortisol, prolactin and growth hormone) was normal. Magnetic resonance imaging (MRI) done prior to the onset of symptomatic raised intracranial pressure revealed two distinct lesions in the suprasellar region (fig. 1a-f). One was a centrally located, pedunculated lesion arising from the hypothalamus which was predominantly iso-intense on $\mathrm{T}_{1^{-}}$and $\mathrm{T}_{2}$-weighted images (WI) (fig. 1a, b). A larger, circumscribed area of $\mathrm{T}_{1}$ - and $\mathrm{T}_{2}$-hypointensity, suggestive of an old bleed (fig. 1c-e), was noted inside this lesion. Seen in an adjacent sagittal cut was a 
distinct lesion which was iso-intense on $\mathrm{T}_{1^{-}}$and $\mathrm{T}_{2}$-WIs (fig. 1f). It had a wide base near the tuberculum sellae and a conical tip directed postero-superiorly. Neither of the lesions enhanced significantly with contrast. There was no evidence of intraventricular hemorrhage or hydrocephalus in these MR images. CT scan done at presentation with raised intracranial pressure revealed a recent bleed in the suprasellar region (fig. $1 \mathrm{~g}$ ), blood in the lateral (fig. $1 \mathrm{~h}$ ) and third ventricles near the region of the foramina of Monro, and resultant gross hydrocephalus (fig. $1 \mathrm{~g}, \mathrm{~h}$ ).

The patient underwent a ventriculo-peritoneal shunt and a follow-on left pterional approach and excision of the lesions. At surgery, there was evident xanthochromia in the sylvian fissure and suprasellar region. Two distinct lesions were noted in the suprasellar region. The larger, pedunculated lesion arising from the hypothalamus was greyish and firm, and contained greenish material which was corresponding to the large, circumscribed, $\mathrm{T}_{1}$ and $\mathrm{T}_{2}$-hypointense area (arrows in fig. 1c-e) on the MRI. Adjacent to this lesion was a smaller, whitish structure with a wide base attached to the dura in the region of the tuberculum sellae, and a tapering, conical free-end posteriorly (fig. 2). The pituitary stalk was seen separately. Both the lesions were completely excised.

On light microscopy, the first lesion arising from the hypothalamus demonstrated glial tissue with neurons lying singly and in clusters, with evidence of dysmorphism (fig. 3a). Hemosiderin, suggestive of hemorrhage (fig. $3 \mathrm{~b}$ ), was noted in this lesion. The greenish material contained fibrin with hemosiderin. These features were consistent with the diagnosis of an $\mathrm{HH}$ with bleed. Sections from the adjacent dural-based lesion showed a mature teratoma, as evidenced by the presence of seromucinous and intestinal glands, adipose tissue, respiratory epithelium and a fragment of cartilage (fig. $3 \mathrm{c}-\mathrm{e}$ ).

Her symptoms of raised intracranial pressure subsided following the shunt surgery. A postoperative MRI revealed significant decrease in ventricular size and no residual lesion (fig. 1i-1). At a follow-up visit 6 months after definitive surgery, she had remained seizure-free while her symptoms of precocious puberty had demonstrated significant regression.

\section{Discussion}

The $\mathrm{HH}$ is a congenital lesion that arises from the tuber cinereum or mammillary bodies. Mostly sporadic, a few of its cases $(10 \%)$ have been reported in association with malformation syndromes like that of Pallister-Hall, McKusick-Kaufman, and Bardet-Biedl [2, 4]. Amongst its reported lesional, intracranial associations are Rathke's cleft cyst [4] and arachnoid cysts, either in the suprasellar region [5] or in the temporo-sylvian region [6-8]. Adding to this small list is our report of a suprasellar teratoma.

Another rare dysembryonic lesion, the teratoma, represents $0.5 \%$ of all intracranial tumors [9]. Common sites of predilection include the pineal, suprasellar and hypothalamic regions. It is classified into mature, immature and malignant types based on histology $[9,10]$. Amongst the unusual pathologies reported to have occurred con-

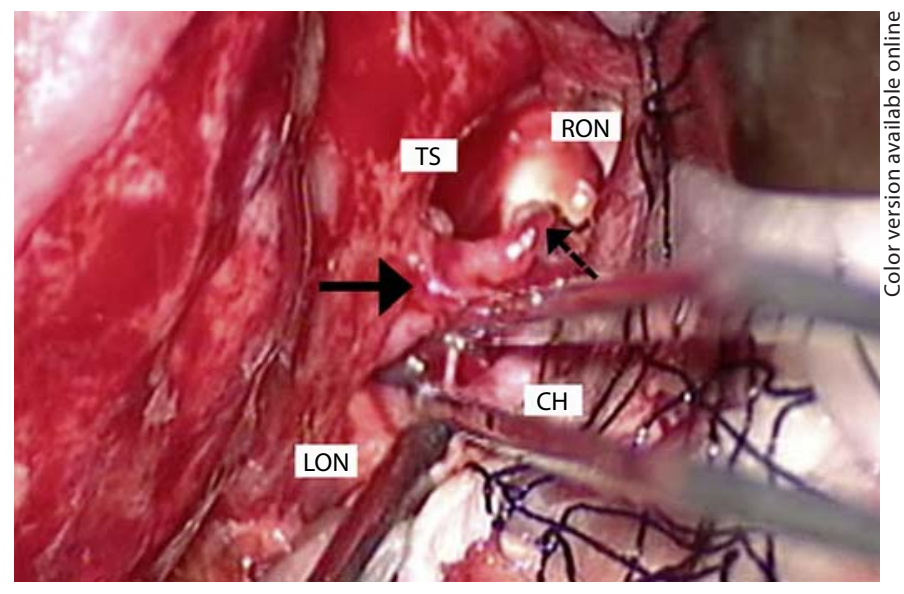

Fig. 2. Intraoperative picture taken after excision of the $\mathrm{HH}$ showing the teratoma with a wide dural base (solid arrow) in the region of the tuberculum sellae (TS), and a free pointed tip (broken arrow) directed posteriorly. $\mathrm{LON}=$ Left optic nerve; $\mathrm{RON}=$ right optic nerve; $\mathrm{CH}=$ optic chiasm.

comitantly with a teratoma are an interparietal encephalocele [11] and spinal dysraphism [12-14]. These unusual associations, like those of the $\mathrm{HH}$, suggest a common genetic basis for pathologies of seemingly different origin.

The mechanism of development of the $\mathrm{HH}$ is largely unclear, resulting in the generation of several hypotheses [3]. One hypothesis relates to the ectopic localization of otherwise normal cellular elements secondary to defects in cell-cell recognition and cell-matrix interference, mechanisms that normally guide neuronal migration along radial glial cells. The absence of appropriate migratory and proliferative stimuli results in local structural abnormalities and an ensuing $\mathrm{HH}$. A second hypothesis is related to an abnormal proliferative potential of normally positioned hamartomous cells. Rarely, this proliferative phenotype persists, resulting in a hypothalamic hamartoblastoma with more primitive and immature neuronal and glial elements [2].

Teratomas in the central nervous system are typically located in midline structures, supporting the theory that they originate from pluripotent cell rests at the sites of early neural tube closure $[9,10,12-14]$. Well-known associations of teratomas in the spinal cord with dysraphic congenital spinal malformations such as spina bifida, syrinx, dermal sinus, split cord, meningomyelocele and lipomeningomyelocele suggest an embryogenetic error related to dysfunction of genetic and cellular inductive mechanisms [12-14]. 

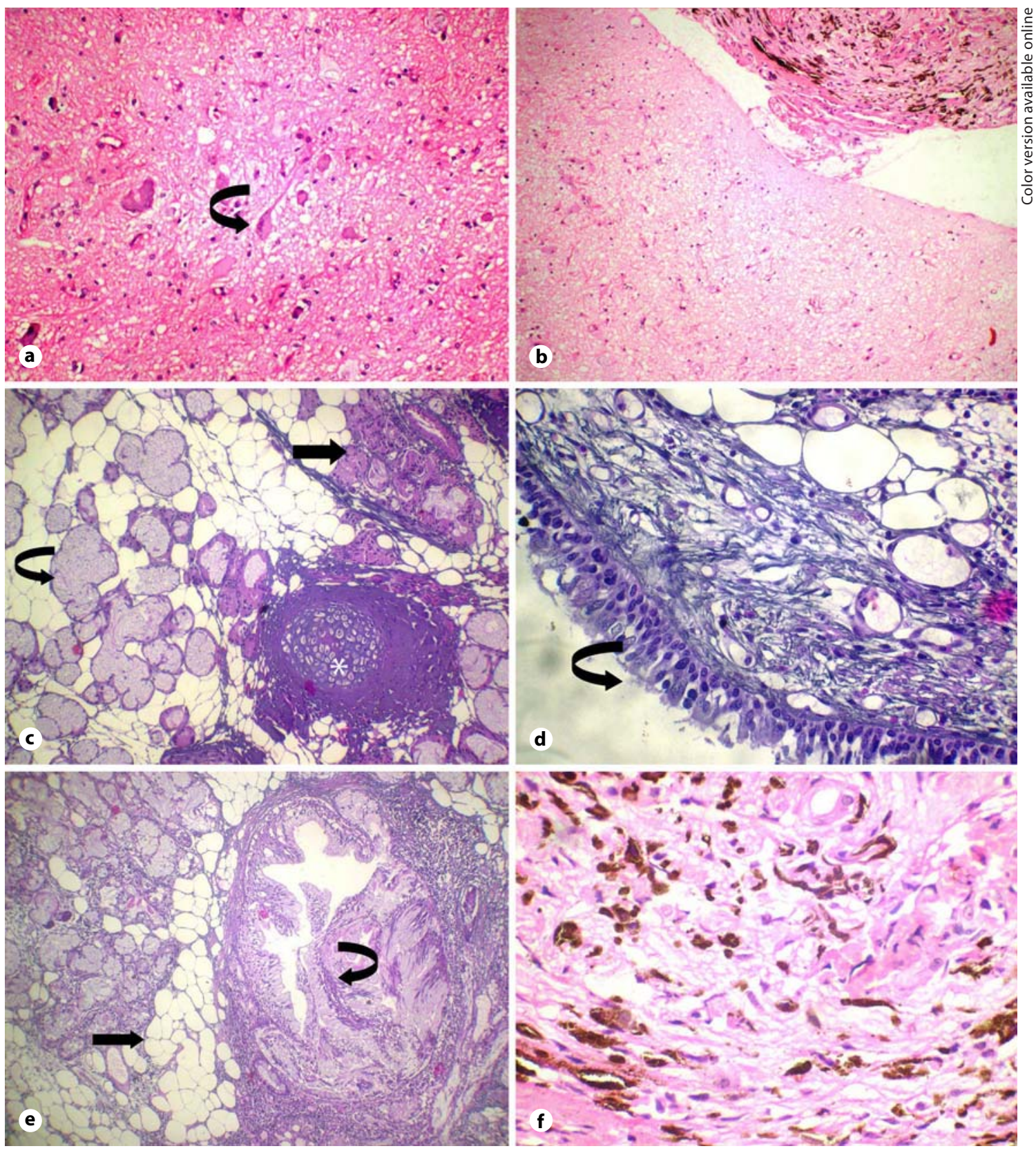

Fig. 3. Paraffin section showing a $\mathrm{HH}$, with clustering of neurons (curved arrow), b hemosiderin pigment in one part of the hamartoma. Paraffin section of the distinct, dural-based lesion showing a mature teratoma with c seromucinous glands (straight and curved arrows), cartilage (asterisk), d respiratory epithelium (curved arrow), and e fat (straight arrow) with intestinal glands. $\mathbf{f}$ Brownish granular hemosiderin pigment in the hamartoma (hematoxylin and eosin: $\mathbf{b}, \mathbf{c}, \mathbf{e} \times 100 ; \mathbf{a}, \mathbf{d}, \mathbf{f} \times 400)$.

In our case, a genetic error causing defective cell-cell recognition and abnormal neuronal migration may have resulted in two different midline pathologies as part of an ontogenic derangement. Abnormal neuronal migration and ectopic localization of relatively normal tissue would have resulted in the $\mathrm{HH}$ on one hand, while misplaced pluripotent cells and a subsequently disordered organogenesis would have resulted in the teratoma on the other.

Although atypical features like cystic change $[3,15]$ and the presence of fat [16] have been reported in the $\mathrm{HH}$, 
hemorrhage has not been documented as yet. Lesions in the hypothalamic region rarely reported to have bled are pilocytic astrocytomas, pilomyxoid astrocytomas and fibrillary astrocytomas [17-23]. Possible causes of tumorrelated hemorrhage include endothelial proliferation and obstruction of the tumor vessels causing necrosis and hemorrhage, disruption of vessels by tumor expansion, tumor infiltration into vessels, or abnormal tumor vascularity [17-24]. Hemorrhage in a hamartoma is rare, with isolated reports in sites like the retina and intestine [25, 26]. A postulated mechanism of hemorrhage in such cases is related to the impingement of surrounding blood vessels by the lesion. In our case, it is conceivable that the significantly sized hamartoma may have impinged on some vessel(s) in the capillary-rich suprasellar region to have caused the recurrent bleeds.

Although gelastic seizures are the prototypic seizures in a case of an $\mathrm{HH}$, other seizure types, including generalized seizures, are known to develop secondary to the spread of seizure activity from the mammillary bodies to the thalamus and cortex via the mammillothalamic tract
[27]. While confirming the intrinsic epileptogenic potential of these lesions by depth electrode placement, Shim et al. [28] reported good control of all $\mathrm{HH}$-associated seizures after disconnection/excision of the lesion. This would explain the disappearance of the generalized seizures in our case following complete resection of the $\mathrm{HH}$.

\section{Conclusion}

This first-of-its-kind report describes the coexistence of a mature suprasellar teratoma with an $\mathrm{HH}$. An additional unreported feature in the case was the evidence of bleed into the hamartoma. A hypothesis is proposed to explain the concurrent occurrence of the hamartoma with the dysontogenetic lesion.

\section{Disclosure Statement}

The authors have no conflicts of interest to disclose.

\section{References}

1 Choh NA, Choh SA: Hypothalamic hamartoma causing precocious puberty in a female child. J Pediatr Endocrinol Metab 2010;23: 433-434.

2 Clarren SK, Alvord EC Jr, Hall JG: Congenital hypothalamic hamartoblastoma, hypopituitarism, imperforate anus, and postaxial polydactyly - a new syndrome? Part II: Neuropathological considerations. Am J Med Genet 1980;7:75-83.

-3 Dorfer C, Kasprian G, Mühlebner A, Czech T: Giant solid-cystic hypothalamic hamartoma. Case report. Neurosurg Focus 2011; 30:E7.

4 Yu-Tze NG, Kerrigan JF, Prenger EC, White WL, Rekate HL: Successful resection of a hypothalamic hamartoma and a Rathke cleft cyst. Case report. J Neurosurg 2005; 102:7880.

5 Mocco J, Lozier AP, Komotar RJ, Silver AJ, Feldstein NA: Hypothalamic hamartoma in association with a suprasellar arachnoid cyst: a case report. Pediatr Neurosurg 2005; 41:105-108

6 Goda M, Tashima A, Isono M, Hori S, Kimba Y: A case of hypothalamic hamartoma associated with arachnoid cyst. Childs Nerv Syst 1999; 15:490-492.
7 Isaka T, Nakatani S, Yoshimine T, Akai F, Taneda M: Asymptomatic hypothalamic hamartoma associated with an arachnoid cyst - case report. Neurol Med Chir 1996;36 725-728.

8 Nishio S, Morioka T, Hamada Y, Kuromaru R, Fukui M: Hypothalamic hamartoma associated with an arachnoid cyst. J Clin Neurosci 2001;8:46-48.

9 Agrawal M, Uppin MS, Patibandla MR, Bhattacharjee S, Panigrahi MK, Saradhi V, Rani JY, Purohit AK, Challa S: Teratomas in central nervous system: a clinico-morphological study with review of literature. Neurol India 2010;58:841-846.

10 Muzumdar D, Goel A, Desai K, Shenoy A: Mature teratoma arising from the sella - case report. Neurol Med Chir 2001;41:356-359.

11 Turgut M, Meteoglu I: Mature teratoma associated with an interparietal encephalocele. Case report. J Neurosurg 2007;106:305-307.

$>12$ Koen JL, McLendon RE, George TM: Intradural spinal teratoma: evidence for a dysembryogenic origin. Report of four cases. J Neurosurg 1998;89:844-851.

13 Makary R, Wolfson D, Dasilva V, Mohammadi A, Sania S: Intramedullary mature teratoma of the cervical spinal cord at C1-2 associated with occult spinal dysraphism in an adult. Case report and review of the literature. J Neurosurg Spine 2007;6:579-84.
14 Muthukumar N: Split cord malformation and cystic teratoma masquerading as lipomeningomyelocele. Childs Nerv Syst 2003;19: 46-49.

-15 Prasad S, Shah J, Patkar D, Gala B, Patankar T: Giant hypothalamic hamartoma with cystic change: report of two cases and review of the literature. Neuroradiology 2000;42:648650.

16 Sharma MC, Gaikwad S, Mahapatra AK, Menon PS, Sarkar C: Hypothalamic hamartoma: report of a case with unusual histologic features. Am J Surg Pathol 1998;22:15381541.

17 Garg A, Chugh M, Gaikwad SB, Chandra PS, Gupta V, Mishra NK, Sharma MC: Juvenile pilocytic astrocytoma presenting with subarachnoid hemorrhage. Case report and review of the literature. J Neurosurg Pediatr 2004;100:525-529.

18 Glew WB: Stimulated pituitary apoplexy: report of an unusual case due to hemorrhage into hypothalamic astrocytoma. Ann Ophthalmol 1977;9:139-142.

19 Golash A, Thorne J, West CG: Low-grade pilocytic astrocytoma presenting as a spontaneous intracerebral hemorrhage in a child. Br J Neurosurg 1998;12:59-62. 
-20 Hamada H, Kurimoto M, Hayashi N, Nagai S, Kurosaki K, Nomoto K, Kanegane H, Nomura K, Endo S: Pilomyxoid astrocytoma in a patient presenting with fatal hemorrhage. Case report. J Neurosurg Pediatr 2008;1: 244-246.

-21 Hwang SL, Huang TY, Chai CY, Howng SL: Hypothalamic juvenile pilocytic astrocytoma presenting with intracerebral hemorrhage. J Formos Med Assoc 1998;97:784-787.
22 Matsumoto K, Akagi K, Abekura M, Maeda Y, Kitagawa M, Ryujin H, Iwasa N: Hypothalamic pilocytic astrocytoma presenting with intratumoral and subarachnoid hemorrhage. Neurol Med Chir 1997;37:849-851.

-23 Sorenson EJ, Silbert PL, Benarroch EE, Jack CR, Parisi JE: Transient amnestic syndrome after spontaneous haemorrhage into a hypothalamic pilocytic astrocytoma. J Neurol Neurosurg Psychiatry 1995;58:761-763.

24 Mandybur TI: Intracranial hemorrhage caused by metastatic tumors. Neurology 1977;27:650-655.

-25 Ghoshal UC, Das Gupta J, Dutta A, Chatterjee B, Acharya AN, Banerjee PK, Choudhuri TK: Isolated myoepithelial duodenal hamartoma presenting with upper gastrointestinal bleed. Indian J Gastroenterol 1998;17:109110 .
26 Kroll AJ, Ricker DP, Robb RM, Albert DM: Vitreous hemorrhage complicating retinal astrocytic hamartoma. Surv Ophthalmol 1981;26:31-38

27 Rosenfeld JV: The evolution of treatment for hypothalamic hamartoma: a personal odyssey. Neurosurg Focus 2011;30:E1.

28 Shim KW, Chang JH, Park YG, Kim HD, Choi, JU, Kim DS: Treatment modality for intractable epilepsy in hypothalamic hamartomatous lesions. Neurosurgery 2008;62: 847-856. 